\title{
Direct and indirect costs of tuberculosis among immigrant patients in the Netherlands
}

\author{
Sandra V Kik*1,2, Sandra PJ Olthof ${ }^{1}$, Jonie TN de Vries ${ }^{1}$, Dick Menzies ${ }^{3}$, \\ Naomi Kincler ${ }^{3}$, Joke van Loenhout-Rooyakkerss ${ }^{4}$ Conny Burdo ${ }^{5}$ and \\ Suzanne Verver ${ }^{1,2}$
}

Address: ${ }^{1}$ Research Unit, KNCV Tuberculosis Foundation, The Hague, the Netherlands, ${ }^{2}$ Center for Infection and Immunity Amsterdam, Academic Medical Center Amsterdam, the Netherlands, ${ }^{3}$ Respiratory Division, McGill University, Montreal, Canada, ${ }^{4}$ Department of Tuberculosis Control, Municipal Health Service Regio Nijmegen, the Netherlands and ${ }^{5}$ Department of Tuberculosis Control, Municipal Public Health Service RotterdamRijnmond, Rotterdam, the Netherlands

Email: Sandra V Kik* - kiks@kncvtbc.nl; Sandra PJ Olthof - sandra_olthof@hotmail.com; Jonie TN de Vries - jonie_d@hotmail.com; Dick Menzies - dick.menzies@mcgill.ca; Naomi Kincler - nkincler@yahoo.ca; Joke van Loenhout-Rooyakkers - jloenhout@ggd-nijmegen.nl; Conny Burdo - burdo_c@hotmail.com; Suzanne Verver - ververs@kncvtbc.nl

* Corresponding author

Published: 5 August 2009

BMC Public Health 2009, 9:283 doi:10.1 186/1471-2458-9-283
Received: 5 January 2009

Accepted: 5 August 2009

This article is available from: http://www.biomedcentral.com//47/-2458/9/283

(C) 2009 Kik et al; licensee BioMed Central Ltd.

This is an Open Access article distributed under the terms of the Creative Commons Attribution License (http://creativecommons.org/licenses/by/2.0), which permits unrestricted use, distribution, and reproduction in any medium, provided the original work is properly cited.

\begin{abstract}
Background: In low tuberculosis (TB) incidence countries TB affects mostly immigrants in the productive age group. Little empirical information is available about direct and indirect TB-related costs that patients face in these high-income countries. We assessed the direct and indirect costs of immigrants with TB in the Netherlands.
\end{abstract}

Methods: A cross-sectional survey at 14 municipal health services and 2 specialized TB hospitals was conducted. Interviews were administered to first or second generation immigrants, 18 years or older, with pulmonary or extrapulmonary TB, who were on treatment for I-6 months. Out of pocket expenditures and time loss, related to TB, was assessed for different phases of the current TB illness.

Results: In total 60 patients were interviewed. Average direct costs spent by households with a TB patient amounted $€ 353$. Most costs were spent when being hospitalized. Time loss (mean $8 \mathrm{I}$ days) was mainly due to hospitalization (19 days) and additional work days lost (60 days), and corresponded with a cost estimation of $€ 2603$.

Conclusion: Even in a country with a good health insurance system that covers medication and consultation costs, patients do have substantial extra expenditures. Furthermore, our patients lost on average 2.7 months of productive days. TB patients are economically vulnerable. 


\section{Background}

Tuberculosis (TB) affects people within the most productive age group and the resultant economic costs for society are high $[1,2]$. Previous studies on the economic aspects of $\mathrm{TB}$ control have focused on health system costs for interventions like screening, or on evaluation of these interventions [3-10]. There is little information about the TB related costs incurred by TB patients and their households throughout the entire illness, including the pre-diagnostic phase. The only studies assessing patient and household costs have been conducted in high TB prevalence and lowincome countries $[6,11-16]$, but are lacking for low-prevalence and high-income countries. Health policy makers need this information to assess the overall economic impact of TB. Even though in most countries diagnostic and treatment services for TB control are offered free of charge, TB patients do have out of pocket expenditures [11,12].

As in many other low-incidence countries, in the Netherlands, immigrants and refugees contribute to a high TB case load, compared to native inhabitants $[3,17,18]$. In 2007 , among the 960 registered TB patients in the Netherlands $592(61 \%)$ were foreign-born. Enrolment in a private health insurance is compulsory for all inhabitants in the Netherlands. Beside the mandatory basic health insurance (approximately $€ 95$ per month), people can additionally choose for a more extended insurance with a higher coverage. Moreover, individuals with a yearly gross income below $€ 26071$ qualify for a health care allowance of maximum $€ 36$ per month. In 2007, the basic health insurance covered all costs of TB medication, most diagnostic tests, doctors' consultation and hospitalisation, but not costs related to travel and food supplements etc. Since immigrants are often faced with lower annual incomes than the non-migrant population, TB related expenditures not covered by the health insurance might be disproportionately higher for immigrants than for non-migrant patients.

In this study we describe the direct and indirect costs of TB among immigrants with TB disease in the Netherlands.

\section{Methods}

\section{Study design and population}

Between April 2007 and October 2007 we conducted a cross-sectional survey at the 14 municipal health services (MHSs) and the two specialized TB hospitals that volunteered to participate in the Netherlands. They were selected based on the largest number of patients, being usually from larger cities. This study was part of a multicentre international study on cost-effectiveness of worldwide interventions, coordinated by McGill University in Montreal, Canada. In this paper we present the data collected in the Netherlands.
We included tuberculosis patients who were a first or second generation immigrants, who were on anti-TB treatment and aged 18 years or older. First generation immigrants were those individuals born in a foreign country and who were living in the Netherlands at the time of diagnosis of active TB. Second generation immigrants were those individuals who were born in the Netherlands, but who had at least one parent that was born abroad.

\section{Data collection}

Patients who fulfilled the inclusion criteria were invited to participate in the study by the nurse from the MHS or specialized TB hospital. One of two trained interviewers explained the study, obtained informed consent and performed an in-depth face-to-face interview. A structured questionnaire was used, developed by McGill University (Montreal, Canada), that had been successfully used in previous studies $[6,10,11]$, and was adapted to the Dutch setting. Patients who were unable to speak Dutch or English were helped by family members or friends who could speak one of these two languages. If necessary a translator assisted by telephone. Interviews were done in a private room, without the presence of any medical staff in order to guarantee the patients' privacy.

Medical information from all TB patients in the Netherlands is registered in the Netherlands Tuberculosis Register (NTR). The NTR-committee and all participating MHSs gave permission to extract anonymous medical data from this register for the study population. To verify if our study population was comparable to all TB patients we compared our study population with all TB patients (who fulfilled the study inclusion criteria) who were diagnosed in 2005. Since complete national data were at the time of the study only available for 2005 we assumed that TB cases notified in the NTR in 2005 were comparable to those of 2007. No ethical approval was needed for this study from the Central Committee on Research Involving Human Subjects (CCMO) as our questionnaire did not involve any intrusive questions.

\section{Costs assessed}

Information about costs was ascertained for different periods starting from the moment of onset of symptoms up to the completion of treatment. Direct costs and time loss during the different periods were asked per visit. Since patients were still under treatment at the moment of the interview, we assumed that the length of their treatment would be comparable with the average treatment length of immigrant patients in 2005; which was 6.4 months for the whole treatment. Patients who received directly observed therapy (DOT) received their medication 3 to 5 times per week at the MHS. The duration of DOT was on average 5.0 months in 2005 according to the Dutch sur- 
veillance data. All costs were extrapolated for the entire treatment period.

\section{Direct costs}

Direct patient costs included all out of pocket expenditures of patients that were attributable to their illness [19]. Direct costs included the costs of transportation to health facilities, costs of extra food (bought during waiting time at the health facility), extra expenditures related to hospitalization (which were not covered by the health insurance) or over the counter medication (such as vitamin B6). These costs were assessed both for the patient as well as for their household members when they had extra expenditures due to the illness of the patient.

\section{Indirect costs}

Indirect patient costs refer to the costs associated with time lost by the patient. This loss of time included visits to the health facilities and hospitalization as well as other time lost due to the inability to work as a result of the illness [19]. Time loss was only collected for the patients themselves. In order to quantify the magnitude of time loss, the number of days lost was multiplied by the estimated income of the patients. Because of the sensitivity of the question, we did not ask the participants their exact income, but asked them to indicate which of 4 categories their income corresponded to. To quantify the indirect costs, the average time loss, in days, was multiplied by the estimated average income of the study population.

\section{Data and statistical analysis}

Questionnaires were double entered by two different persons into a standardized database. Data were analysed with SPSS 14.0. Costs and time loss were compared between patients with pulmonary tuberculosis (PTB) and patients with extrapulmonary tuberculosis (ETB). Patients with both PTB and ETB were classified as PTB. Odds ratio's (OR) for being included in our study compared to all immigrant patient (regardless of their inclusion on our study) were determined by logistic regression analysis, to determine the representativeness of the patients included in our study for all immigrant patients in 2005. P-values were calculated by chi-square test, independent t-test or non-parametric tests as appropriate. While data on costs and time loss was not normally distributed, we reported mean values to allow comparison with other published cost estimates. In our tables also median values are given.

\section{Results}

\section{Patient characteristics}

During the study period, 60 patients fulfilled the inclusion criteria and consented to participate. In general, our study population included more males (63\%) than females $(37 \%)$. The majority of the patients included in the study were 25 to 44 years old and most patients were first generation immigrants from Africa or Asia (Table 1). Compared to all immigrant patients diagnosed in the Netherlands in 2005, our study population was slightly younger and included significantly fewer persons with impaired immunity (i.e. patients with HIV, diabetes, malignancy, an organ transplantation, renal insufficiency or other causes of immune suppression or who used TNF$\alpha$ inhibitors). None of the four interviewed patients with an impaired immunity was known to be HIV positive.

Out of 60 patients, 31 (52\%) had PTB, 23 had (38\%) ETB and $6(10 \%)$ suffered from both PTB and ЕTB. We did not observe any significant differences between characteristics of the interviewed patients with PTB and ETB, but ЕTB patients tended to be older than PTB patients (Table 2). Out of 60 participants, 34 (57\%) were unemployed at the time of the interview. Nine $(26 \%)$ of the 34 unemployed patients were asylum seekers, who are not allowed to have a paid job during their entrance procedure. Eight other patients $(13 \%)$ stated that their unemployment was due to their TB illness. A lot of the patients $(48 \%)$ were living alone in a household. Forty three percent of the immigrants with TB reported that their net household income before diagnosis was less than $€ 1000$ per month. Postdiagnosis this percentage increased slightly to $50 \%$. Six patients reported a reduction of their income, while 3 reported an increase since their diagnosis. Except for 2 patients, $58(97 \%)$ had a health insurance.

\section{Direct patient costs}

Direct costs of immigrants during the entire TB illness averaged €353 (median €190) (Table 3). Almost all patients (58/60) had some direct costs during their illness. Expenditures of patients varied widely and total direct costs of patients ranged from $€ 0$ to $€ 3961$. Most patients had out of pocket expenditures during the follow-up visits and the diagnostic period. Costs during the pre-diagnostic period were slightly higher for patients with ETB (mean $€ 10$, sd 18.8) compared to patients with PTB (mean €3, sd 7.4, t-test p-value $=0.04$ ). No differences in costs during the other periods were observed for patients with different types of tuberculosis. Patient delay, defined as the period between first symptoms and first contact with a health care provider, did not differ between PTB patients (mean 2.5 months, sd 6.9) and ETB patients (mean 3.0 months, sd $4.7, \mathrm{p}=0.79$ ). Most costs were incurred if patients were hospitalized. While $28(47 \%)$ patients had been hospitalized before, during or after their TB diagnosis; mean costs during hospitalization were $€ 105$ on average. During hospitalization most costs were spent on food and other items such as the use of a TV or telephone. Additional costs consisted mainly of additional vitamins, energy drinks and food supplements. One patient 
Table I: Comparison between the interviewed immigrants in the study and all immigrants with tuberculosis diagnosed in 2005

\begin{tabular}{|c|c|c|c|}
\hline & Immigrant TB patients in 2005, N (\%)* & Study population, N (\%)* & $P$-value Chi-square \\
\hline Total & $762(100)$ & $60(100)$ & \\
\hline Sex & & & 0.49 \\
\hline Male & $448(59)$ & $38(63)$ & \\
\hline Female & $3 \mid 4(4 \mid)$ & $22(37)$ & \\
\hline Age (yr) & & & 0.08 \\
\hline $18-24$ & $150(20)$ & $18(30)$ & \\
\hline $25-44$ & $386(5 \mathrm{I})$ & $33(55)$ & \\
\hline $45-64$ & $154(20)$ & $8(13)$ & \\
\hline$\geq 65$ & $71(9)$ & $\mathrm{I}(2)$ & \\
\hline Unknown & $\mathrm{I}(0)$ & $0(0)$ & \\
\hline Generation & & & 0.43 \\
\hline First generation immigrant & $718(94)$ & $58(97)$ & \\
\hline Second generation immigrant & $44(6)$ & $2(3)$ & \\
\hline Region of origin & & & 0.44 \\
\hline Europe & $92(12)$ & $3(5)$ & \\
\hline America (Central and South) & $72(9)$ & $6(10)$ & \\
\hline America (North) & $I(0)$ & $0(0)$ & \\
\hline Asia & $249(33)$ & $18(30)$ & \\
\hline Africa & $338(44)$ & $33(55)$ & \\
\hline Unknown & $10(\mathrm{I})$ & $0(0)$ & \\
\hline Localisation of TB & & & 0.69 \\
\hline Pulmonary & $357(47)$ & $31(52)$ & \\
\hline Extrapulmonary & $305(40)$ & $23(38)$ & \\
\hline Pulmonary and extrapulmonary & $100(13)$ & $6(10)$ & \\
\hline Culture result & & & 0.83 \\
\hline Positive & $531(70)$ & $44(73)$ & \\
\hline Negative & $91(12)$ & $6(10)$ & \\
\hline Not done/unknown & $140(18)$ & $10(17)$ & \\
\hline Previously diagnosed with TB & & & 0.13 \\
\hline No & $611(80)$ & $54(90)$ & \\
\hline Yes & $46(6)$ & $3(5)$ & \\
\hline Unknown & $105(14)$ & $3(5)$ & \\
\hline Treatment regime & & & $<0.01$ \\
\hline Standard $(4 \mathrm{HRZ}(\mathrm{E}) / 2 \mathrm{HR}(\mathrm{E}))$ & $542(7 \mathrm{I})$ & $43(72)$ & \\
\hline Other & $220(29)$ & $9(15)$ & \\
\hline Unknown & $0(0)$ & $8(13)$ & \\
\hline Impaired immunity & & & $<0.01$ \\
\hline No & $282(37)$ & $40(67)$ & \\
\hline Yes & 140 (18) & $4(7)$ & \\
\hline Missing & $340(45)$ & $16(27)$ & \\
\hline $\begin{array}{l}\text { Hospitalization } \\
\text { (during TB treatment for at least } 7 \text { days) }\end{array}$ & & & 0.16 \\
\hline No & $438(58)$ & $29(48)$ & \\
\hline Yes & $232(30)$ & $19(32) \ddagger$ & \\
\hline Unknown & $92(12)$ & $12(20)$ & \\
\hline
\end{tabular}

Definition of abbreviations: $\mathrm{H}$ = isoniazid; $\mathrm{R}=$ rifampin; $\mathrm{Z}=$ pyrazinamid; $\mathrm{E}=$ ethambutol;

* Column percentages are given

¥ This number differs from that in Table 2 because a different definition for hospitalization is used in the NTR-database.

reported to have extra high rent costs due to $\mathrm{TB}$, which explains the maximum of $€ 2400$. Although in general costs for laboratory tests, consultation and most medication are covered by the health insurance, some patients reported that they had incurred costs on these items. In general, direct costs were spent on additional food supplements, travel to visits the health facilities and food that was bought during waiting times (Figure 1).

\section{Indirect costs}

On average patients lost 81 days of normal productivity due to their TB illness (median 60 days) (Table 3). All patients had time loss (ranging from 0.5-637 days), mainly due to travel and consultation time at different health care facilities. ETB patients had on average significantly more time loss during their pre-diagnostic period than PTB patients (mean $=0.24$ vs. 0.07 days respectively, 
Table 2: Socio-economic characteristics of immigrants with pulmonary tuberculosis compared to immigrants with extrapulmonary tuberculosis

\begin{tabular}{|c|c|c|c|c|}
\hline & All TB cases, $\mathbf{N}(\%)^{*}$ & Pulmonary TB cases, N (\%)* $\ddagger$ & Extrapulmonary TB cases, $\mathbf{N}(\%)^{*}$ & p-valuet \\
\hline Total & 60 & 37 & 23 & \\
\hline \multicolumn{5}{|l|}{ Sex } \\
\hline Male & $38(63)$ & $24(65)$ & $14(6 \mathrm{I})$ & 0.76 \\
\hline Female & $22(37)$ & $13(35)$ & $9(39)$ & \\
\hline \multicolumn{5}{|l|}{ Age (yr) } \\
\hline $18-24$ & $18(30)$ & $13(34)$ & $5(23)$ & 0.06 \\
\hline $25-44$ & $33(55)$ & $23(61)$ & $10(46)$ & \\
\hline $45-64$ & $8(13)$ & $2(5)$ & $6(27)$ & \\
\hline$\geq 65$ & $\mathrm{I}(2)$ & $0(0)$ & I (5) & \\
\hline \multicolumn{5}{|l|}{ Region of origin } \\
\hline Europe & $3(5)$ & $3(8)$ & $0(0)$ & 0.25 \\
\hline America (Central and South) & $6(10)$ & $2(5)$ & $4(18)$ & \\
\hline Asia & $18(30)$ & $12(32)$ & $6(27)$ & \\
\hline Africa & $33(55)$ & $21(55)$ & $12(54)$ & \\
\hline \multicolumn{5}{|l|}{ Immigration status } \\
\hline Landed immigrant & $33(55)$ & I5 (4I) & $18(79)$ & 0.12 \\
\hline Immigrant applicant (asylum seeker) & $12(20)$ & $10(27)$ & $2(9)$ & \\
\hline Illegal immigrant & $4(7)$ & $3(8)$ & I (4) & \\
\hline Accepted refugee & $3(5)$ & $2(5)$ & I (4) & \\
\hline Second generation immigrant & $2(3)$ & $2(5)$ & 0 & \\
\hline Student & $6(10)$ & $5(14)$ & I (4) & \\
\hline \multicolumn{5}{|l|}{ Level of education } \\
\hline No education & $6(10)$ & $5(14)$ & I (5) & 0.53 \\
\hline Primary school & $11(18)$ & $6(15)$ & $5(22)$ & \\
\hline Some high school (not completed) & $10(17)$ & $5(14)$ & $5(22)$ & \\
\hline High school & $18(30)$ & $10(27)$ & $8(35)$ & \\
\hline Above high school & $15(25)$ & II (30) & $4(17)$ & \\
\hline \multicolumn{5}{|l|}{ Employment status } \\
\hline Employed or student & $26(43)$ & $16(43)$ & $10(43)$ & 0.99 \\
\hline Unemployed & $34(57)$ & $21(57)$ & $13(57)$ & \\
\hline \multicolumn{5}{|l|}{$\begin{array}{l}\text { Unemployment due to TB } \\
(n=34)\end{array}$} \\
\hline Yes & $8(24)$ & $5(24)$ & $3(23)$ & 0.96 \\
\hline No & $26(76)$ & $16(76)$ & $10(77)$ & \\
\hline \multicolumn{5}{|l|}{$\begin{array}{l}\text { Pre-diagnostic period; } \\
\text { Monthly household income } \\
\text { (after tax rebate) }\end{array}$} \\
\hline$<€ 100$ & $4(7)$ & $4(\mathrm{II})$ & 0 & 0.27 \\
\hline$€ 100-€ 499$ & $10(17)$ & $6(16)$ & $4(17)$ & \\
\hline$€ 500-€ 999$ & $12(20)$ & $5(14)$ & $7(30)$ & \\
\hline$\geq € 1000$ & $33(55)$ & $21(57)$ & $12(52)$ & \\
\hline Unknown & $\mathrm{I}(2)$ & I (3) & $0(0)$ & \\
\hline \multicolumn{5}{|l|}{$\begin{array}{l}\text { Post-diagnostic period; } \\
\text { Monthly household income } \\
\text { (after tax rebate) }\end{array}$} \\
\hline$<€ 100$ & $2(3)$ & $2(5)$ & 0 & 0.82 \\
\hline$€ 100-€ 499$ & $14(23)$ & $9(24)$ & $5(22)$ & \\
\hline$€ 500-€ 999$ & $14(23)$ & $8(22)$ & $6(26)$ & \\
\hline$\geq € 1000$ & $28(47)$ & $17(46)$ & $11(48)$ & \\
\hline Unknown & $2(3)$ & I (3) & I (4) & \\
\hline \multicolumn{5}{|l|}{$\begin{array}{l}\text { Difference in income after } \\
\text { diagnosis of TB }\end{array}$} \\
\hline Yes, income increased & $3(5)$ & $2(5)$ & I (4) & 0.98 \\
\hline Yes, income decreased & $6(10)$ & $4(11)$ & $2(9)$ & \\
\hline No, no change in income & $49(82)$ & $30(8 I)$ & $19(83)$ & \\
\hline Unknown & $2(3)$ & I (3) & I (4) & \\
\hline
\end{tabular}


t-test $\mathrm{p}$-value $=0.01$ ). There was no difference between the time loss during other phases of the disease between ETB and PTB patients. The inability to work accounted for most time loss per patient and was on average 60.5 days. Hospitalizations led to an additional 18.6 days of time loss and visits to health facilities accounted for 1.6 days.

The Statistics Netherlands (CBS) estimated the average national disposable yearly income per household (after tax rebate and reduction of social insurance and health insurance) at $€ 29,400$ in the Netherlands in 2005 [20]. Since half of the patients in our study reported their income to be less than $€ 1000$ per month, we decided that a yearly household income of $€ 12,000 \quad(12 * € 1000)$ would be a more appropriate estimate of the average income of the participants in our study. To quantify the indirect costs, the average time loss, in days, was multiplied by $€ 32.25$ ( $€ 1000 / 31$; making no difference between time loss during working days and weekend days). Consequently, the mean indirect costs corresponded with $€ 2603$ per patient.

\section{Discussion}

This study demonstrates the economic burden that immigrant TB patients in the Netherlands face during their TB illness. We show that, even in a high income country where most medical costs are covered by the mandatory health insurance, immigrants with tuberculosis do have extra out of pocket expenditures. Furthermore, immigrant patients lost 81 productive days due to their illness. Costs and time loss during the pre-diagnostic period were slightly higher for patients with ETB compared to those with PTB, which is possibly due to the added investigations needed to diagnose extrapulmonary tuberculosis and exclude other pathology. Our study confirms that TB patients are from vulnerable groups, having a high unemployment rate both before their disease and even higher during disease, and a lower average income than the general population.

Out of pocket expenditures were comparable with $3 \%$ (€353/€12000) of the average annual income of the patients. These costs may be a considerable part of their disposable income after the payment of all monthly fixed costs such as rent, marginal costs (such as electricity and water) and insurances. Moreover, these costs are all faced during the time of TB disease and thus spend in a period of around 6 months. A quarter of the interviewed TB patients were asylum seekers, who often have even less money to spend. Some authors have concluded that a cost burden greater than $10 \%$ will be catastrophic for the household [15,21]. It is debatable if this percentage can be applied to both low and high income countries. The amount of extra costs spend will depend on the available income. For example, quite a number of patients reported to spend extra money on food supplements. It can be

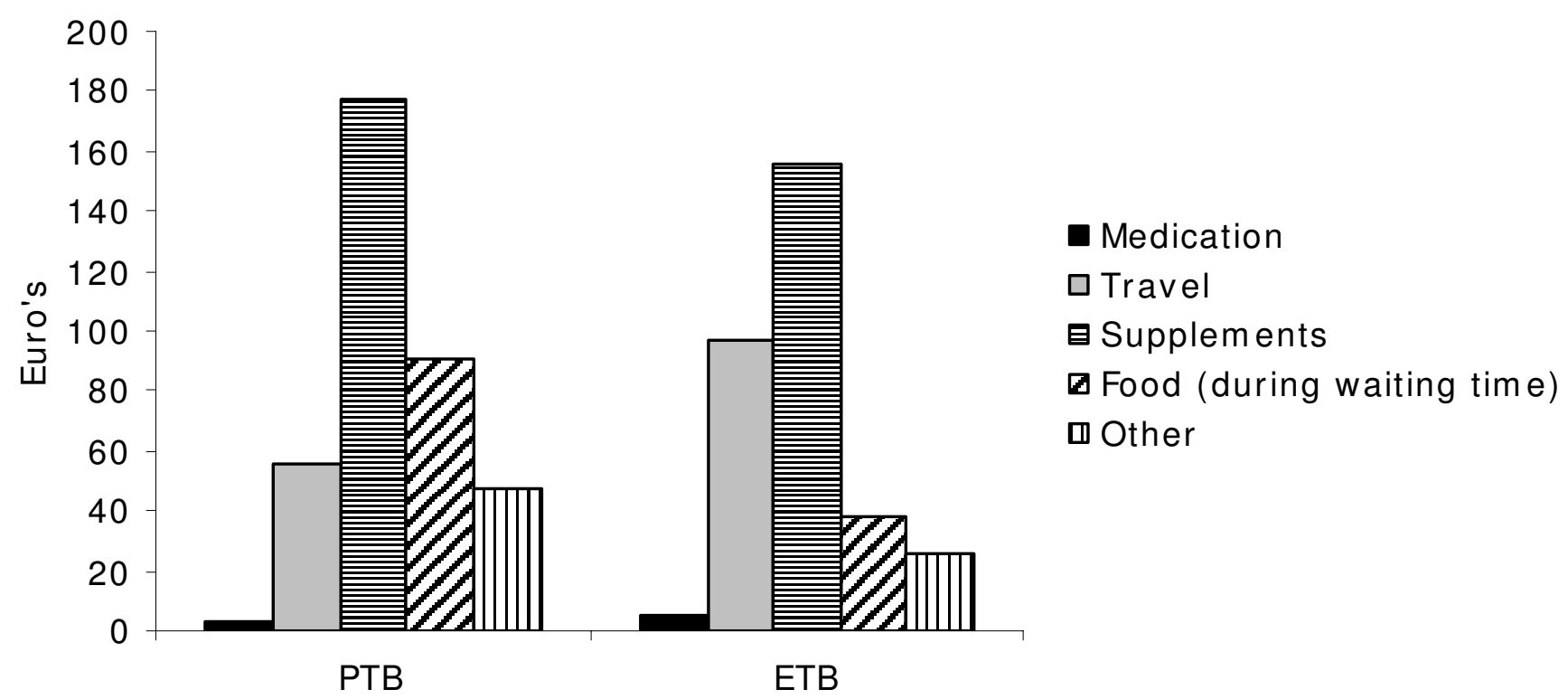

Figure I

Type of direct costs incurred by immigrants with pulmonary or extrapulmonary tuberculosis (mean costs in euro's) during the whole TB illness period. Definition of abbreviations: PTB = pulmonary tuberculosis; ETB = extrapulmonary tuberculosis. 
Table 3: Mean direct costs and time loss of immigrants with tuberculosis during different periods of their illness $(n=60)$

\begin{tabular}{|c|c|c|c|c|}
\hline & \multicolumn{4}{|c|}{ Direct costs (euro's) } \\
\hline & \multicolumn{2}{|c|}{ Patients reporting costs during this period } & \multicolumn{2}{|c|}{ All patients $(n=60)$} \\
\hline & $\mathrm{N}(\%)^{*}$ & Mean costs (min-max) $\dagger$ & Mean costs $\dagger$ & Median costs (IQR) \\
\hline Pre-diagnostic period & $23(38)$ & $€ I 5(€ I-€ 72)$ & $€ 6$ & $0(0-4)$ \\
\hline Diagnostic period & $36(60)$ & $€ 27(€|-€| 90)$ & $€ 16$ & $5(0-16)$ \\
\hline Follow-up visits & $49(82)$ & $€ 49(€ 5-€ 195)$ & $€ 40$ & $27(10-60)$ \\
\hline DOT visits & $13(22)$ & $€ 72(€ 3-€ 4 \mid 7)$ & $€ 16$ & $0(0-0)$ \\
\hline Hospitalization & $21(35)$ & $€ 301(€ 2-€ 3960)$ & $€ 105$ & $0(0-5 I)$ \\
\hline Additional costs & $39(65)$ & $€ 263(€ 4-€ 2400)$ & $€ І 7 \mid$ & $64(0-25 I)$ \\
\hline \multirow[t]{4}{*}{ TOTAL } & $58(97)$ & $€ 365(€ 3-€ 3961)$ & $€ 353$ & $190(74-399)$ \\
\hline & \multicolumn{4}{|c|}{ Time loss (days) } \\
\hline & \multicolumn{2}{|c|}{ Patients reporting time loss during this period } & \multicolumn{2}{|c|}{ All patients $(n=60)$} \\
\hline & $\mathrm{N}(\%)^{*}$ & Mean time loss, days (min-max) & Mean time loss & Median time loss (IQR) \\
\hline Pre-diagnostic period & $41(68)$ & $0.2(0.0-1.8)$ & 0.1 & $0.1(0-0.2)$ \\
\hline Diagnostic period & $42(70)$ & $0.3(0.0-1.2)$ & 0.2 & $0.2(0-0.4)$ \\
\hline Follow-up visits & $60(100)$ & $0.6(0.18-2.0)$ & 0.6 & $0.4(0.3-0.8)$ \\
\hline DOT visits & $31(52)$ & $1.3(0.2-6.6)$ & 0.7 & $0.1(0-0.7)$ \\
\hline Hospitalization & $28(47)$ & $39.9(1.0-180.0)$ & 18.6 & $0(0-21.0)$ \\
\hline Other workdays lost & $39(65)$ & $93.0(21.0-600.0)$ & 60.5 & $31.0(0-90.0)$ \\
\hline TOTAL & $60(100)$ & $80.7(0.5-637.2)$ & 80.7 & $59.7(4.6-121.5)$ \\
\hline
\end{tabular}

Definition of abbreviations: $I Q R$ = inter-quarter range; DOT = directly observed therapy

* Column percentages are given

$\dagger$ Costs are rounded to the nearest integer.

questioned whether patients with little income will (or need to) spend costs on these additional items, when they can't pay them. Furthermore, coping strategies may have resulted in differences in expenditures between patients, but we did not assess how patients handled these extra expenditures.

Opposed to our study, earlier studies on direct and indirect costs due to $\mathrm{TB}$ were done in low-income countries. While the total direct and indirect costs of our study population accounted for approximately $25 \%$ of their annual income $(€ 353+€ 2956 / € 12000 * 100 \%)$, the total costs accounted for a considerable higher percentage in these low-income countries $[6,11,14,15]$. For example, a survey in Haiti estimated out of pocket expenses and lost income due to TB illness to be $76 \%$ of the average per capita income of Haitians, while a study from India showed that TB related costs accounted for $40 \%$ of the household income during TB illness $[6,14]$. The differences between these studies and ours may be explained by different social background, insurance system and a higher income per inhabitant in our high-income country.

Although time loss had not affected the income of all interviewed tuberculosis patients we did express the loss of time in costs. The height of the indirect costs may therefore be an overestimation of the costs faced by the individ- ual patient, since these costs are mostly carried by the society. In the Netherlands, the social security system provides a benefit to all inhabitants who are jobless. Furthermore, individuals who have a job and become ill, will mostly receive their regular income. However, $57 \%$ of the interviewed immigrant patients was jobless and a quarter of them attributed their unemployment to their tuberculosis illness. An additional ten percent of the employed patients reported that their household income decreased due to their TB illness. The unemployment rate among TB patients even before their disease is higher than the national unemployment rate among non-western immigrants living in the Netherlands $(16 \%)$. This in turn is much higher than that among the autochthonous Dutch population (4\%). Consequently, their estimated income levels differ. Although we studied the TB related costs only among immigrant patients, it can be expected that these costs will not be much different for other TB patients, since most expenditures were spent on travel and food related items. However, when expressed as a percentage of the income, these TB related expenditures will be a smaller proportion of the income among the autochthonous $\mathrm{TB}$ patients.

Our study had some limitations. First of all our study population, a convenience sample of TB patients of the participating centres, was not completely representative for all 
immigrant TB patients. We included younger patients and fewer patients with an impaired immunity. Both factors may have led to an underestimation of the cost estimates, since older patients and those who are immunocompromised may have atypical presentations of $\mathrm{TB}$, delayed diagnosis and more complex treatment needing more medical attention during follow-up. Secondly, many of the interviewed immigrants were unable to speak Dutch or English. This made it sometimes difficult to obtain reliable information, but on the basis of a face-to-face interview and with the aid of a translator the interviewers were still able to obtain detailed information about the patient costs. Face-to-face interviews are a good method to obtain detailed information from the past and diminish recall bias

[22].

Lastly, we did not ask for the exact income details. In other studies the Gross National Product (GNP) and data from surveys by National Statistics Office were used $[6,12]$. The average income we used in this study may be underestimated since we did not know the maximum income in the highest income category. If so, this will have resulted in an underestimation of the indirect costs, and have led to an overestimation of the relative direct costs expressed as a percentage of the average income.

\section{Conclusion}

In conclusion, this study showed that immigrants with $\mathrm{TB}$ are economically burdened in the Netherlands. Even in a country with a good health insurance system that covers medication and consultation costs, patients do have substantial extra expenditures. TB patients are economically vulnerable.

\section{Competing interests}

The authors declare that they have no competing interests.

\section{Authors' contributions}

SK participated in study design, performed statistical analysis, and wrote the draft manuscript. SO participated in the interviews of the patients, performed data entry and analysis, and wrote the report that was the basis of this manuscript. JV participated in the interviews of the patients, performed data entry and analysis, and wrote the report that was the basis of this manuscript. DM conceived the study and gave critical comments on the draft manuscript. NK conceived the study, trained the interviewers and coordinated the data collection, and gave critical comments on the draft manuscript. JLR participated in the data collection, and gave critical comments on the draft manuscript. CB participated in the data collection and gave critical comments on the draft manuscript. SV participated in the study design, coordinated the study and gave critical comments on the draft manuscript. All authors read and approved the final manuscript.

\section{Acknowledgements}

We are grateful to all participating municipal health services GGD Rotterdam-Rijnmond, Hulpverleningsdienst GGD Groningen (locations Groningen and Assen), Hulpverlening Gelderland Midden, GGD Fryslân, GGD Regio IJssel-Vecht, GGD Eindhoven, GGD Regio Nijmegen, GGD Den Haag, GGD Hart voor Brabant, GGD Noord- en Midden-Limburg, GGD Regio Twente, GGD Rivierenland, GGD Gelre-lJssel, Hulpverleningsdienst Flevoland, and the two specialized TB hospitals: Dekkerswald Universitair longcentrum en Beatrixoord Centrum voor Revalidatie/Tuberculose for their cooperation and effort during the study and all patients who were willing to cooperate with our study. The authors are thankful to Olivia Oxlade from McGill University in Montreal for her assistance; Nico Kalisvaart for his assistance with the retrieval of data from the NTR; Baukje Vegter and Connie Erkens for their advice during the execution of the study and Maiza Campos-Ponce from the Free University and Esther de Bekker-Grob from the Erasmus University Medical Centre for their advice.

\section{References}

I. Floyd K, Pantoja A, Dye C: Financing tuberculosis control: the role of a global financial monitoring system. Bull World Health Organ 2007, 85(5):334-340.

2. WHO: Global tuberculosis control: surveillance, planning, financing: WHO report 2008. Geneva, Switzerland: WHO Press; 2008.

3. Dasgupta K, Schwartzman K, Marchand R, Tennenbaum TN, Brassard $P$, Menzies D: Comparison of cost-effectiveness of tuberculosis screening of close contacts and foreign-born populations. Am J Respir Crit Care Med 2000, I62(6):2079-2086.

4. Diel R, Nienhaus A, Schaberg T: Cost-effectiveness of isoniazid chemoprevention in close contacts. Eur Respir J 2005, 26(3):465-473.

5. Floyd K: Costs and effectiveness - the impact of economic studies on TB control. Tuberculosis (Edinb) 2003, 83(I3): $187-200$

6. Jacquet V, Morose W, Schwartzman K, Oxlade O, Barr G, Grimard F, Menzies D: Impact of DOTS expansion on tuberculosis related outcomes and costs in Haiti. BMC Public Health 2006, 6:209.

7. Porco TC, Lewis B, Marseille E, Grinsdale J, Flood JM, Royce SE: Cost-effectiveness of tuberculosis evaluation and treatment of newly-arrived immigrants. BMC Public Health 2006, 6: 157.

8. Rubado DJ, Choi D, Becker T, Winthrop K, Schafer S: Determining the cost of tuberculosis case management in a low-incidence state. Int J Tuberc Lung Dis 2008, I 2(3):301-307.

9. Schwartzman K, Menzies D: Tuberculosis screening of immigrants to low-prevalence countries. A cost-effectiveness analysis. Am J Respir Crit Care Med 2000, I6I(3 Pt I):780-789.

10. Schwartzman K, Oxlade O, Barr RG, Grimard F, Acosta I, Baez J, Ferreira E, Melgen RE, Morose W, Salgado AC, et al: Domestic returns from investment in the control of tuberculosis in other countries. N Engl J Med 2005, 353(10): 1008-1020.

II. Aspler A, Menzies D, Oxlade O, Banda J, Mwenge L, Godfrey-Faussett $\mathrm{P}$, Ayles $\mathrm{H}$ : Cost of tuberculosis diagnosis and treatment from the patient perspective in Lusaka, Zambia. Int J Tuberc Lung Dis 2008, I 2(8):928-935.

12. Croft RA, Croft RP: Expenditure and loss of income incurred by tuberculosis patients before reaching effective treatment in Bangladesh. Int J Tuberc Lung Dis 1998, 2(3):252-254.

13. Kamolratanakul P, Sawert H, Kongsin S, Lertmaharit S, Sriwongsa J, Na-Songkhla S, Wangmane S, Jittimanee S, Payanandana V: Economic impact of tuberculosis at the household level. Int J Tuberc Lung Dis 1999, 3(7):596-602.

14. Rajeswari R, Balasubramanian R, Muniyandi M, Geetharamani S, Thresa X, Venkatesan P: Socio-economic impact of tuberculosis on patients and family in India. Int J Tuberc Lung Dis 1999, 3(10):869-877.

15. Russell S: The economic burden of illness for households in developing countries: a review of studies focusing on malaria, tuberculosis, and human immunodeficiency virus/ acquired immunodeficiency syndrome. Am J Trop Med Hyg 2004, 7 I (2 Suppl): I47-I55. 
16. Wyss K, Kilima P, Lorenz N: Costs of tuberculosis for households and health care providers in Dar es Salaam, Tanzania. Trop Med Int Health 200I, 6(I):60-68.

17. Cain KP, Benoit SR, Winston CA, Mac Kenzie WR: Tuberculosis among foreign-born persons in the United States. Jama 2008, 300(4):405-4I2.

18. Falzon D, Ait-Belghiti $F$ : What is tuberculosis surveillance in the European Union telling us? Clin Infect Dis 2007, 44(10): $|26|-\mid 267$.

19. Drummond MF, Sculpher MJ, Torrance GW, O'Brien BJ, Stoddart GL: Methods for the economic evaluation of health care programmes. 3rd edition. New York: Oxford University Press; 2005

20. CBS: Statistics Netherlands 2005 [http://statline.cbs.nl/StatWeb/publi cation/ ?DM=SLNL\&PA $=70843$ ned\&D $|=a \& D 2=0 \& D 3=0 \& D 4=a \& H D R=G|$ $\mathrm{G} 2, \mathrm{G} 3 \& S T B=T \& V W=T$.

21. Ranson MK: Reduction of catastrophic health care expenditures by a community-based health insurance scheme in Gujarat, India: current experiences and challenges. Bull World Health Organ 2002, 80(8):613-62I.

22. Bouter LM, van Dongen MCJM: Epidemiologisch onderzoek, opzet en interpretatie. 3rd edition. Houten, Netherlands: Bohn Stafleu van Loghum BV; 1995.

\section{Pre-publication history}

The pre-publication history for this paper can be accessed here:

http://www.biomedcentral.com/1471-2458/9/283/pre

pub

Publish with Bio Med Central and every scientist can read your work free of charge

"BioMed Central will be the most significant development for disseminating the results of biomedical research in our lifetime. "

Sir Paul Nurse, Cancer Research UK

Your research papers will be:

- available free of charge to the entire biomedical community

- peer reviewed and published immediately upon acceptance

- cited in PubMed and archived on PubMed Central

- yours - you keep the copyright 